Recibido: 30-04-2014

Aceptado: 20-08-2014

Palabras clave: neuronas espejo, empatía, aprendizaje por imitación.

Keywords: mirror neurons, empathy, learning by imitation.

Olga Teresa Gonzalez

Sarmiento UNIFÉ ogonzalez@unife.edu.pe

\section{Lo único que nos separa de los otros es la piel: las neuronas espejo}

\section{The only thing that separates us from others is skin: the mirror neurons}

\section{Olga Teresa Gonzalez Sarmiento}

RESUMEN. Según estudios que se han desprendido de la identificación del genoma humano, existe una coincidencia del 99\% en los genes que componen nuestra especie, es decir, somos mucho más parecidos unos a otros de lo que creemos.

Otro descubrimiento, esta vez no de origen intencional, dio como resultado a que sepamos más acerca de un tipo especial de neuronas: las neuronas espejo, tema central del presente artículo, que explora lo referido a este tipo tan especial de neuronas y su relación con la capacidad que tiene el ser humano de educarse, aprender y, por supuesto, comprender a los demás de una manera más eficiente. Las relaciones interpersonales se basan en la capacidad que tenemos de captar de manera exitosa las intenciones y motivos del comportamiento de los demás. Para lograrlo, nuestros circuitos neuronales trabajan arduamente en el proceso de identificarnos con los demás.

Es decir, cuando interactuamos nos encontramos en estados neuronales muy semejantes, como si estuviéramos realizando las mismas acciones, captando las intenciones de los otros o experimentando las mismas emociones. Este artículo explora básicamente estos aspectos y otros relativos a la importancia de las neuronas espejo en el proceso del aprendizaje humano.

ABSTRACT. According to studies resulting from the identification of human genome, it exists a coincidence of $99 \%$ in genes composing our species, that is to say, we are much more similar one another than we believe.

Another discovery, this time unintentionally, gave us as a result to know more about a special type of neurons: the mirror neurons, central theme of this article, which explores all regarding this very special type of neurons and its relation with the ability of human being for educate himself, learn and, of course, understand others in a more efficient way.

Interpersonal relationships are based on the ability to capture intentions and reasons for the behavior of others successfully. To achieve this, our neuronal circuits are working hard in the process to identify ourselves with others.

That is, when we interact, we are in very similar neuronal states, as we would be doing the same actions, getting the intention of the others or undergoing the same emotions. The present article basically analyses these aspects and another related to the mirror neurons importance in the human learning. 


\section{UNIFÉ - EPG}
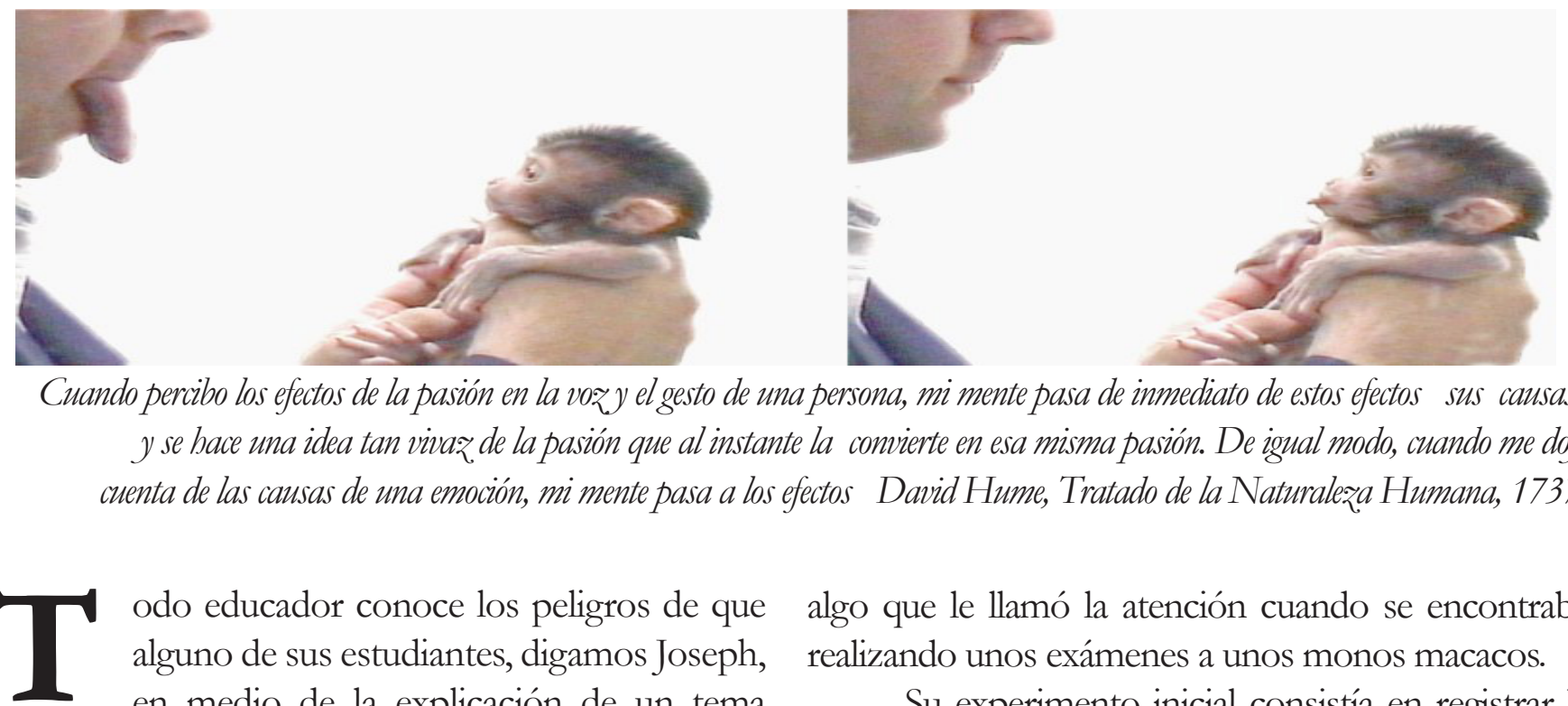

uando percibo los efectos de la pasión en la vozy el gesto de una persona, mi mente pasa de inmediato de estos efectos sus causas, y se hace una idea tan vivaz de la pasión que al instante la convierte en esa misma pasión. De igual modo, cuando me doy cuenta de las causas de una emoción, mi mente pasa a los efectos David Hume, Tratado de la Naturaleza Humana, 1737

$\mathbf{T}$

odo educador conoce los peligros de que alguno de sus estudiantes, digamos Joseph, en medio de la explicación de un tema especialmente importante inicie un gran bostezo..., será quizás porque tememos que nuestra actuación no se encuentre a la altura de las circunstancias?, quizás haya algo de eso en nuestra preocupación pero, si somos sinceros lo que realmente nos preocupa es que al bostezo inicial se le unan otros procedentes de los alumnos Piero, Mariana, Linda o quizás también Javier o quién sabe?, echando por tierra nuestro esfuerzo...

Termina esa clase y salimos al pasillo, alguien nos sonríe, casi sin pensarlo nos encontramos devolviéndole la sonrisa, de dónde la/lo conozco?, más allá una compañera nos muestra una entrevista donde una joven llora pues reclama por la muerte de su padre, instantáneamente nuestro semblante cambia, de alguna manera se refleja en él la empatía con las emociones que experimenta en ese momento la muchacha.

Finalmente, regresamos a casa y nuestra mascota se sienta a observarnos como tomamos algún alimento y, de pronto se relame, ojo, ella/él ya comió, pero igual realiza un gesto de placer al mirarnos, como si se encontrara, efectivamente, probando algo exquisito...

Se reconoció en alguna de estas situaciones descritas?, en una?, en todas?, a qué se debe?

Giacomo Rizzolatti (1996), neurobiólogo italiano y profesor de la Universidad de Parma se hizo, probablemente la misma pregunta cuando observó algo que le llamó la atención cuando se encontraba realizando unos exámenes a unos monos macacos.

Su experimento inicial consistía en registrar la actividad nerviosa de las neuronas de unos monos macacos en zonas de la corteza premotora en el momento en que realizaban algún movimiento voluntario como tomar una fruta o un maní para llevárselos a la boca.

Con fines de registro los investigadores habían implantado en el cerebro de los animales electrodos sumamente finos, capaces de registrar la actividad de una única neurona, con estos datos, lo que pretendían el Dr. Rizzolatti y su equipo, Leonardo Fogassi y Vittorio Gallese era identificar la actividad de determinadas neuronas individuales, sin embargo, con la buena fortuna de su lado, halló mucho más de lo que esperaba.

En principio, el experimento trataba de que al coger alguno de los monos un maní, una de las neuronas motoras emitía un impulso eléctrico que los investigadores registraban con ayuda de instrumentos, sin embargo, un día sucedió algo fortuito.

Rizzolatti recuerda que "cuando Leonardo Fogassi, parado al lado de una frutera, tomó un plátano, observamos que algunas de las neuronas del mono reaccionaron, pero: ¿cómo podía suceder esto si el animal no se había movido? Al principio pensamos que era un error en nuestra técnica de medición o quizá un fallo del equipo; luego, comprobamos que todo funcionaba bien y que las reacciones de la neurona ocurrían cada vez que repetíamos el movimiento, mientras el macaco lo observaba" 
Había sucedido una serendipia,(serendipity) neologismo acuñado por Horace Walpole en 1754; se trataba de un hallazgo afortunado, una casualidad como las que salvaban a los tres príncipes del cuento persa "Los tres príncipes de Serendip".

Qué había sucedido? Entró al laboratorio un investigador comiendo un helado y... se encendieron los monitores que estaban conectados al cerebro del macaco, lo mismo ocurrió cuando otro de los colegas, Fogassi, tomó un plátano,- sin que el animal que observaba la acción se moviera-, sonó la alerta que indicaba que había habido un impulso eléctrico en una neurona motora, como si el animal hubiese realizado el movimiento, pero él no se había movido en absoluto!

Lo que verdaderamente sorprendió a Rizzolatti fue descubrir que, aparte de las neuronas responsables del movimiento, que se activaban cuando el macaco tomaba la fruta, también estas neuronas de la corteza premotora se activaban cuando un mono observaba a un congénere realizar la acción... o a un humano...

Habría que agregar también, que el estudio descubrió que se trataba no solo de ver una acción para que se activara la respuesta, también se halló que podía darse esta situación si se escuchaba el realizar la acción, es decir, si tomamos el ejemplo del maní, se activaba la respuesta del macaco al escuchar que alguien estaba rompiendo la cáscara del fruto aunque no estuviera precisamente viendo lo que sucedía.

Lo más interesante de todo ese proceso es que el Dr. Rizzolatti y su equipo descubrieron que las neuronas activadas correspondían exactamente al mismo grupo requerido para echar a andar el movimiento en la persona que lo ejecutaba. Se había descubierto a las denominadas neuronas espejo o especulares.

Sin embargo cuando Rizzolatti hizo pública la investigación no despertó mucho interés en la comunidad científica e, incluso, la renombrada revista Nature rechazó publicar la información por considerar que se trataba de un tema intrascendente para la mayoría, afortunadamente, gracias a posteriores estudios con ayuda de imágenes por resonancia magnética se descubrió que las neuronas espejo también se encontraban y de forma abundante en el cerebro humano, motivo por el que se reconsideró la trascendencia de los hallazgos realizados por el equipo de la Universidad de Parma.

Fue entonces que el descubrimiento de Rizzolatti se convirtió en algo muy importante, según el reconocido científico Vilayanur Ramachandrán (2005), "el descubrimiento de las neuronas espejo hará por la psicología, lo que el ADN por la biología".

Al respecto, el citado neurocientífico, especialista en secuelas relacionadas con dolores en miembros fantasma, cuenta que realizó pruebas con un paciente que había perdido una mano en la Guerra del Golfo.

Al pedirle mirar a otra persona a la que Ramachandrán acariciaba y daba golpecitos en la mano, el paciente exclamó que sentía en el miembro fantasma las acciones que estaba observando. Igual efecto fue registrado por el científico cuando examinó a otros pacientes en idénticas circunstancias.

Pero, el experimento fue mucho más allá, inclusive algunos de los pacientes experimentaron alivio en su mano inexistente cuando observaron que otra persona se encontraba recibiendo un masaje en la misma zona corporal (Ramachandrán, 2012).

Algo quizás menos científico pero que grafica de idéntica manera el trabajo realizado por las neuronas espejo se presentó en un programa de televisión hace un tiempo atrás.

Se realizó un experimento donde a unos voluntarios se les cubría una de sus manos, la izquierda, con un pequeño parapeto y se les pedía colocaran la mano derecha sobre una mesa, al lado de un objeto en silicona con forma de mano, que simulaba ser su mano izquierda.

El experimento consistía en que se acariciaba con una pluma la mano de silicona, mientras que, inesperadamente, se le propinaba un fuerte golpe con un martillo, resultó sorprendente, el susto que experimentaron los voluntarios al ver que el miembro artificial era atacado, reaccionaron como si alguien, en efecto, les hubiese golpeado con un martillo. Era el efecto especular.

Este interesante grupo de neuronas, las denominadas "espejo" fue descubierto en 1996 por el equipo de Giacomo Rizzolatti de la Universidad 


\section{UNIFÉ - EPG}

de Parma y es estudiado actualmente por muchos neurocientíficos en el mundo.

Hasta el momento, producto de estos estudios se ha descubierto que las neuronas espejo se sitúan en las proximidades del Área de Broca, en la corteza premotora, circunvolución frontal inferior, región F5, una sección del cerebro humano dedicada a la producción del habla, el procesamiento del lenguaje y la comprensión, así como en el lóbulo parietal inferior, en las mismas áreas cerebrales que en el cerebro de un mono macaco.

También se ha hallado que este tipo de células nerviosas se activa, específicamente, en dos situaciones: cuando la persona o el animal ejecutan la acción, o, cuando la persona observa mientras otro realiza la acción.

Marco Iacoboni (2010), quien se desempeña como profesor de Psiquiatría y Ciencias del Comportamiento y es Director del Laboratorio de Estimulación Magnética Transcraneal en el Centro de Cartografía Cerebral Ahmanson - Lovelace de la Escuela de Medicina de la UCLA, en una entrevista que da a EduardPunset narra que realizó un experimento donde aplicó la técnica denominada estimulación magnética transcraneal, una práctica a través de la cual se produce una lesión temporal en determinada área del cerebro, sin consecuencias posteriores y con fines únicamente de experimentación.

Iacoboni y su equipo utilizaron la técnica de estimulación magnética transcraneal para inhabilitar temporalmente el área de Broca en una serie de participantes al experimento y comprobaron que, una vez inutilizada dicha área, los sujetos no podían imitar más!, por lo tanto, como resultado de este estudio se sugiere que existe un vínculo muy fuerte entre las denominadas neuronas espejo y la capacidad de imitación que poseemos los seres humanos.

En el caso de los simios se desconoce la función del mencionado tipo de neuronas en esa especie, solo se sabe que los neonatos son capaces de imitar los movimientos del rostro humano, pero lo hacen por un período corto, luego, cuando ya son adultos, pierden esa habilidad. Por lo que se cree que en los simios, las neuronas espejo sirven únicamente para entender lo que está haciendo otro congénere.

Iacoboni (2010) afirma que, si alguna persona experimentara un daño en sus neuronas espejo, es probable que pueda imitar lo que otros seres humanos hacen pero sin empatía, es decir, sin comprender qué están experimentando en ese momento, sin captar sentimientos, sin entender en qué estado mental se encuentra el otro respecto a lo que él está haciendo. Se trataría, entonces, de una "lectura sin sentimiento", sin conexiones entre las dos mentes, sería algo vacío de significado.

Asimismo, se ha descubierto que dichas neuronas reproducen, a través de su función refleja, exactamente la misma actividad neuronal correspondiente a la actividad percibida, es decir como si se tratara de un espejo, de allí su nombre.

Dicho de otro modo, es como si quien observa una acción, la realizara pero sin actuarla, lo que sucede es a nivel del encéfalo, sin que pueda ser percibida a simple vista y solo puede ser detectada a través de instrumentos sofisticados tales como la resonancia magnética.

Nos recuerda el principio del cine, presenciamos una película, nos emocionamos, nos sorprendemos, reímos, lloramos, nos compadecemos, como si de la vida misma se tratase, en una palabra, nos identificamos a través de nuestro sistema de neuronas espejo con los protagonistas, vivimos esas emociones a través de ellos.

Esta tendencia a la imitación que poseemos los seres humanos es, indudablemente, muy distinta a la que presentan los primates. Por ejemplo, cuando un ser humano,- uno que se dedica a la mímica- simula pelar un caramelo y llevárselo a la boca, si es otro ser humano el que observa la acción, este se "conecta" y se activa su sistema de neuronas especulares, es decir, lo imagina, lo "vive" a través del otro, sin embargo, no sucede lo mismo con nuestros primos los primates, ellos pueden observar dicha acción - la mímica- pero, en este caso, su sistema de neuronas en espejo no se activa, no se "conecta", no demuestran imaginación.

Rizzolatti (2004) afirma que "un cerebro que actúa es un cerebro que comprende", ese sería el 
motivo por el que los primates no llegan a entender la intención del mimo cuando "pela" su caramelo.

En este sentido, se considera que una de las funciones principales de las neuronas espejo sería el de interpretar las acciones de los demás. También se ha hallado en los experimentos que un grupo de este sistema de neuronas podría estar especializado en detectar la intencionalidad en los actos de las personas; por lo que nos ayudarían a predecir las acciones subsiguientes que podría realizar el sujeto que observamos.

Otra de las funciones importantes que realiza el sistema especular, es la de conectarnos con las emociones que experimentan los otros. Para este fin se han realizado estudios de la actividad cerebral vivida por participantes a diversos experimentos, en los que se medía la capacidad de empatía, mediante la observación de expresiones faciales y corporales asociadas a diversas emociones.

Ambos aspectos estudiados, - el de predecir la intencionalidad de los demás así como el reconocer e interiorizar su estado emocional- son, sin lugar a dudas, habilidades de sobrevivencia a nivel social para los seres humanos.

Asimismo, se ha descubierto que con ayuda de las neuronas espejo, somos capaces de comprender a los demás pues nos permiten vincularnos con ellos desde un punto de vista mental y emocional (Iacoboni, 2009).

Se cree, además, que el papel de dichas neuronas fue fundamental para el desarrollo y evolución del lenguaje humano pues le permitieron al hombre prehistórico imitar las vocalizaciones de sus congéneres $\mathrm{y}$ aprender a interpretar sus intenciones.

Por lo expuesto, si unimos los aspectos de la adquisición de un lenguaje y la capacidad de aprender en base a la imitación, encontraremos los requisitos necesarios para haber desarrollado la cultura, lo que nos convierte en los humanos que somos actualmente, es el camino por el que hemos reunido, siglo tras siglo, milenio tras milenio, el cúmulo de conocimientos que hasta ahora poseemos.

El Dr. Ramachandrán, director del Center of Brain and Cognition de la Universidad de California, lo explica a través de una TED TALK: "Yo defiendo la idea de que lo que ocurrió entonces fue la aparición repentina de un sistema sofisticado de neuronas espejo que permitió emular e imitar las acciones de otras personas".

Por ejemplo, si un homo sapiens, (algunos afirman que sucedió previamente, inclusive desde el homo habilis), en un momento dado, descubre que puede obtener fuego frotando dos guijarros, es muy probable que otro de sus congéneres lo imite de inmediato, generando una cadena de imitaciones, este proceso no hubiera podido ser posible si no contáramos, como especie, con un sistema de neuronas espejo muy sofisticado que nos permitió comprender y emular acciones de los demás.

Algunos afirman que lo mismo sucedió con el lenguaje, en ese momento, estrechamente asociado a la elaboración de herramientas, cuya elaboración era bastante sofisticada, y que solo podía enseñarse con ayuda de la comunicación, de la imitación de sonidos, es decir, con ayuda del sistema especular.

El aprendizaje por imitación también está presente hoy en día cuando somos pequeños y nuestros padres nos enseñan lo básico, a hablar, a desenvolvernos adecuadamente en un medio social, a escuchar a los demás, a ser respetuosos y considerados, etc., sin embargo, no son solamente nuestros padres los que nos forman (o deforman), lo hacen también los medios de comunicación social, cuyos contenidos consumimos libremente, día a día.

Un tema que deforma y que, lamentablemente, es recurrente en la programación diaria, en televisión de señal abierta, son las noticias con fuerte carga de violencia, mostradas con mucha crudeza, sin tener en cuenta quiénes se encuentran al otro lado de la pantalla.

Muchos de nosotros somos testigos de cómo se muestran diariamente situaciones explícitas de violencia: asesinatos, secuestros, golpizas, etc.

$\mathrm{Al}$ observar este tipo de noticias, más de una vez me he preguntado si el que se difundan, así, tan libremente, como parte de un noticiero, no hace sino exacerbar la repetición de los mismos hechos por algunos de los televidentes. 


\section{UNIFÉ - EPG}

Es así que los hallazgos sobre el funcionamiento de las neuronas espejo y el tratamiento científico de la tendencia a imitar de los seres humanos, nos debería de conducir a un cambio radical en el tratamiento de la información relativa a la violencia, por parte de los medios de comunicación social, optando por un tratamiento más ético de la información, más conducente a la conciliación, al respeto, a la solidaridad y, por supuesto, al desarrollo humano como individuos y como sociedad.

En este sentido, el Profesor Iacoboni considera fundamental que la sociedad y las organizaciones fomentenla creación dereferencias de comportamiento y valores positivos, ¿por qué no mostrar acciones constructivas de personas que se superan, que tienen comportamientos resilientes?, ¿por qué no difundirlos como tema central de los noticieros, como una propuesta mucho más constructiva y enriquecedora que lo que nos comunican a diario las escenas de violencia que observamos en los noticieros?

Como probablemente nos ha mostrado la experiencia, si llegamos a un grupo que sonríe, que es acogedor, nos terminamos sintiendo mucho mejor, más a gusto, contagiados por esas actitudes positivas, cómo lo logramos?, pues, indudablemente, se debe a la intervención de nuestro sistema de neuronas espejo, que nos permiten aprender de los demás, ser empáticos, comprender al otro, anticiparnos, desenvolvernos en una sociedad compuesta por una gran variedad de individuos... Ahora la explicación de lo que sucede cuenta ya con una base neurocientífica, se llama NEURONAS ESPEJO.

\section{Referencias}

Corballis, M. (2010). Mirror Neurons and the evolution of Language. En Brain \& Language. pp. 25-35. New York: Oxford University Press.

Iacoboni, M. (2009) Las neuronas espejo: empatía, neuropolítica, autismo, imitación o de cómo entendemos a los otros. Buenos Aires, Argentina: Katz.

Ramachandrán, V. S. (2012). Lo que el cerebro nos dice: los misterios de la mente humana al descubierto. Barcelona, España: Paidós.
Redes (2010). Redes 56: Mentes conectadas sin brijerias. Recuperado de http://www.redesparalaciencia. com/2644/redes/2010/redes-56-mentesconectadas-sin-brujeria

Rizzolatti, G., Sinigaglia, C. (2006). Las neuronas espejo: los mecanismos de la empatía emocional. Barcelona, España: Paidós. 